discussion. (1) The incidence of side effects needs to be established. Our data will be discussed with Wellcome with a view to investigating the further cases reported direct to us. (2) Information about these side effects, if established, must be made more widely available to doctors, pharmacists, and the general public. (3) From the correspondence it seems likely that the side effects of these preparations are well known by individual parents, doctors, and pharmacists, yet this information seems to have failed to reach either the manufacturers or the Committee on Safety of Medicines. If the incidence of side effects is as great as seems likely, this must clearly point to a failure in the system of reporting of side effects of drugs widely given to children. Alternative methods of reporting of side effects in children need to be examined with particular reference to medicines purchased over the counter.

J A Sills

A J NunN

Alder Huv Children's Hospital,

Liverpool L12 $2 \mathrm{AP}$

R J SANKEY

Ninewells Hospital,

Dundec

\section{Neuroleptic malignant syndrome}

SIR,-The leading article by Dr E Szabadi (12 May, p 1399) prompts us to describe a schizophrenic patient who required artificial ventilation for respiratory failure induced by flupenthixol.

The 29 year old man had been given a one week course of haloperidol and chlorpromazine followed by a depot injection of flupenthixo $(40 \mathrm{mg})$ seven days before admission for an exacerbation of his schizophrenia. While an inpatient in a psychiatric hospital he had become gradually more withdrawn and uncommunicative and had also developed a dry cough. He was transferred to our care and on arrival was febrile $\left(40^{\circ} \mathrm{C}\right)$, sweaty, tachypnoeic tachycardic, and hypotensive. He had signs of severe Parkinsonism with marked akinesia and rigidity. Over a few hours his condition deteriorated and he began to produce tenacious discoloured phlegm. He became so parkinsonian that he was unable to maintain adequate respiratory effort and developed ventilatory failure. He had a white cell count of $13.6 \times 10^{\circ}$ but all other investigations, including a lumbar puncture and computed tomography of the skull, gave normal results. He was treated with intravenous antibiotics and benztropine and was ventilated for three days. His recovery was slow with intermittent episodes of sweating, hypotension, and tachypnoea. Eventually he was discharged four weeks after admission, but was still troubled by bradykinesia and stiffness, which persisted for 10 weeks after the initial injection of flupenthixol.

Neuroleptic malignant syndrome is being increasingly recognised as a sericus side effect of neuroleptic drugs. It carries a formidable mortality of $20^{\circ} \mathrm{o}$, mostly due to respiratory failure. ${ }^{1}$ Our patient exhibited a severe disturbance of pyramidal, extrapyramidal, and autonomic systems and would undoubtedly have died without ventilatory support. A constant feature in patients with this syndrome seems to be a fluctuating fever for which no infectious cause can be found. Our case emphasises the need for swift intervention in the management of these patients whose condition can deteriorate very rapidly. Im- mediate withdrawal of the offending drug combined with antiparkinsonian treatment and full supportive care including ventilation if necessary, may prove to be life saving.

1 Bates

Mayday Hospital

Surrey $C R 47 Y$ Heath

R J Courtenay-Evans

Caroff SN. The neuroleptic malignant syndrome Clin Psychiatry 1980;41:79-83.

\section{Medicine in the United States}

SIR,-Dr Gordon Wolstenholme presents a remarkably concise and accurate summary of medical practice in America (21 April, p 1213). He made one error that I would like to correct. He stated, "The National Institutes of Health also have the greatest of medical information services, the Medical Library of Congress." In fact this great medical information service is the National Library of Medicine. It is unrelated to the Library of Congress and the National Agricultural Library, the other two great national libraries in the United States. The medical information system that is now developing in America under the aegis of the National Library of Medicine is directly attributable to the American polymath John Shaw Billings, the "father" of Index Medicus. In the next decade, with adequate support from Congress, the National Library of Medicine should lead American medicine into a network of medical communications that was no dreamed of a decade ago.

\section{Nicholas E Davies}

Piedmont Hospital,

Georgia 30309

SIR,-Dr Gordon Wolstenholme's analysis of the medical profession in the United States (21 April, p 1213) is not "largely subjective and superficial" as he feared. He does, however, make some overgeneralisations and erroneous points concerning the "family doctor."

The term "family doctor" in the United States, is used to denote a physician who has completed three years of postgraduate (residency) training in the field of family practice. Before 1969 family practice was not considered a specialty in its own right and physicians were general practitioners who may not have completed more than one year of training beyond medical school. Many of those physicians, by completing their specialty exams, have since become family physicians. The physician in most states must take a recertifying examination every five years and, as in other specialties, must also show evidence, in the form of credits, for remaining active in continuing education. Family practice here is now well accepted as a specialty along with the many other primary care specialties. Thos physicians who are "aggressively competent in their

The number and (percentages) of residents in major specialties in the United States from 1 September 1979 to 1 September 1982

\begin{tabular}{lcccc}
\hline Specialty & 1979 & 1980 & 1981 & 1982 \\
\hline Family practice & $6552(10)$ & $6344(10)$ & $7004(10)$ & $7040(10)$ \\
Internal medicine & $16580(26)$ & $15964(26)$ & $17537(26)$ & $17185(25)$ \\
Obstetrics and gynaccology & $4496(7)$ & $4221(7)$ & $4705(7)$ & $4702(7)$ \\
Paediatrics & $5603(8)$ & $5171(8)$ & $5961(9)$ & $5720(8)$ \\
Psychiatry & $3901(6)$ & $3911(6)$ & $4336(6)$ & $4235(6)$ \\
Surgery & $7689(12)$ & $7440(12)$ & $8105(12)$ & $8064(12)$ \\
\hline $\begin{array}{l}\text { Total residents in all } \\
\text { specialties }\end{array}$ & 64615 & 61465 & 68217 & 69142 \\
\hline
\end{tabular}

own small spheres" we would tend to call subspecialists. This, obviously, is all a matter of terminology and one might ask to what relevance ?

The emergence of family practice as a specialty has resulted in real and increasing competition for medical school graduates. Family practice is by no means declining, as implied by Dr Wolstenholme's article (see table). ${ }^{1}$ 'The demand for family physicians is shown by the increase in the number of openings for first year residents in family practice rising from 2371 in $1980-1$ to 2553 in 1983-4.

Figures issued by the American Academy of Family Physicians showed an increase in the number of residents enrolled in family practice residency training from 290 in 1970 to 7409 in 1983, with a corresponding rise in numbers in residency programmes from 15 in 1969 to 388 in 1983. The acceptance of family practice as a specialty is not evenly distributed throughout the United States. On the northeast coast, for example, there is a lower percentage of medical school graduates opting for family practice, and it is more difficult for family physicians to obtain privileges in disciplines such as obstetrics and coronary care medicine in the university hospitals. ${ }^{2}$

It is true that in 1940 a higher percentage of physicians were in general practice than now still operating within primary care specialties. In practice the numbers have increased from 51653 in 1973 to 58231 in 1981. As a percentthis represents a change from $15^{\circ} \%$ in 1973 to only $15.2 \%$ in 1981 . The rule of supply and demand has unfortunately not been applied to many other specialties to the extent that in order to survive many other specialists have had to expand their field of practice. To date, The specialty has been trying to stay abreast of the renewed interest in a more holistic approach to medical care and a rekindling of the original concept of the family doctor. I certainly hope that I have not decided to devote my career to training young physicians in a field that others feel is becoming obsolete.

SHARNE S SHEEHEY

St Michael Family Practice Residency,

Wisconsin, USA

' Crowley AE. Medical education in the United States 1982-1983. JAMA 1983;250:1501-1624.

W'eiss BD. Hospital privileges for family physicians at university hospitals. I Fam Pract 1984;18:747-53.

\section{Working in America}

SIR,-I am sometimes asked to give advice to considering working in the United States. American medicine is organised differently from British medicine. I have encountered a British doctor who could not feed his family on what his fellowship paid, a British surgeon who was unhappy because his fellowship was $100 \%$ bench research with no operative surgery, and British doctors who were conbut a considerable number of physicians are age of the total number of physicians in practice there is still a shortage of family physicians. doctors from the United Kingdom who are 